\title{
0 essencial e 0 acessório na formação de jornalistas (Depoimentos)
}

\begin{abstract}
No Outono de 2003, a redacção da revista Comunicação e Sociedade enviou a um conjunto de pessoas ligadas directa ou indirectamente ao jornalismo o convite para que participassem neste número da revista, através de um depoimento curto, centrado na seguinte questão: "Tendo em conta o quadro sociocultural em que os jornalistas exercem a profissão, quais os aspectos que julga serem centrais e quais os secundários, a considerar na respectiva formação?”. Publicam-se a seguir os depoimentos recebidos.
\end{abstract}

\section{Doutores em actualidade}

Adelino Gomes*

É claro para mim que o jornalista deve ter uma forte formação cultural de base. Acrescentarei que à partida me parece indiferente que ramos específicos do saber essa formação deve aprofundar. Do ponto de vista dos interesses da redacção direi até que convinha que fossem os mais diversos. Para um jornal (como para uma emissora de televisão ou de rádio) será bom contar entre os seus profissionais com gente capaz de descodificar os vários temas com que a redacção se confronta em permanência.

Nenhum outro profissional precisa tantas vezes de responder a tantos desafios de tão variada espécie. A notícia, matéria-prima do jornalismo, não conhece fronteiras. A redacção ideal será por isso aquela que contenha no seu seio gente capacitada para tratar jornalisticamente (noticiando, reportando, entrevistando, analisando, comentando) acontecimentos, fenómenos, personalidades de áreas que vão da política ao desporto, da literatura às ciências, do direito à economia e finanças, das artes ao ambiente, ao passado e ao futuro da Humanidade.

Percebe-se pelo que acabo de escrever que não me parece essencial para o exercício competente da profissão obter um diploma universitário em Ciências da Comunicação ou em Jornalismo. Mas numa redacção que eu pudesse formar $a b$ initio procuraria ter alguns (bons) diplomados nesta área.

\footnotetext{
* Jornalista no Público.
} 
Para os que seguem tal variante, um bom curso, salvo melhor opinião, deverá privilegiar a Língua Portuguesa, História (universal, claro, mas também a portuguesa), a Política (idem, idem) e as Relações Internacionais, a Economia e Gestão, a(s) Literatura(s) a História dos Media e as Teorias da Comunicação. Juntando-lhe, desejavelmente logo no primeiro ano, mas pelo menos a partir do terceiro, o estudo das práticas jornalísticas nos diferentes meios.

Para estes e para os outros (oriundos de outras licenciaturas) não prescindiria de uma passagem por uma espécie de pós-graduação "técnica" num curso de âmbito profissional do tipo do que o CENJOR já deu e eu gostaria de ver melhorado e aceite pelas diferentes universidades. Neste curso, insistiria de novo no português, por razões infelizmente mais do que óbvias.

Em resumo: um diploma não é condição nem necessária nem suficiente para se ser jornalista. O que não quer dizer que não ajude e muitíssimo. Mas, ironia à parte, mais do que um diploma, do jornalista - licenciado ou não (eu não o sou e não me orgulho disso) - espera-se que seja uma espécie de doutor em formação contínua. Pois se lhe exige que passe todos os dias no exame da actualidade, matéria base do seu trabalho, tão vasta como vasto é o campo dos saberes, tão complexa como complexo é o mundo em que nos movemos.

Só desta forma pagaremos o privilégio que a sociedade nos concede ao permitir-nos exercer uma profissão sem igual.

\section{Uma ponte óbvia entre dois territórios}

Carlos Pinto Coelho*

O ensino e a formação de jovens jornalistas são dois territórios distintos. Por vezes conflituantes. Quase sempre desgarrados, na prática portuguesa de hoje.

Digo muita vez aos meus alunos finalistas da Escola Superior de Abrantes que a sua preparação teórica é das mais completas dos curricula disponíveis em Portugal, mas que a sua inserção real nas redacções dos jornais, rádios e televisões vai ser penosa.

Não há, na conjuntura de refreio economicista que governa os patrões dos media, privados ou públicos, espaço e ânimo para uma antiga prática de acolhimento dos recém-chegados ao Jornalismo, que era a de lhes conceder acompanhamento. Acompanhamento efectivo e tantas vezes afectivo, como me aconteceu na velha redacção do Diário de Notícias onde o jovem estagiário e finalista de Direito que era eu encontrou gente mais velha disponível para corrigir erros, mandar reescrever prosas e ensinar a vitalidade prática do métier.

Hoje não. Os jovens licenciados que logram (sabe-se lá tantas vezes como) entrada num estágio são abusados desde a primeira hora como carne tenra, disponível e sobretudo barata. Lançados logo no primeiro dia para a rua da reportagem, sem uma linha 
de documentação preparatória e sem uma palavra-guia, sem norma nem norte, acabam por editar sozinhos a sua peça final e ela "passa" directamente para o consumidor. Nem sequer há tempo, depois disso, para uma conversa pedagógica de revisão. E quando vem o dia seguinte tudo se repete, e assim sucessivamente até que chega o final do "estágio". Quando este termina, acontece ou o desemprego camuflado num part-time em pizzaria ou o pior: um contrato formal como profissional de um Jornalismo que se não apreendeu, não se sedimentou nem sofreu emendas, e que se vai praticar com leviano garbo e inocente ignorância.

Não se veja nestas considerações outra coisa diferente do que o que elas significam: o fosso enorme e aberrante que existe entre os melhores pergaminhos curriculares académicos e a voracidade pungente do mercado de trabalho mediático.

Ou seja:

Podem ser diversas as origens do "saber fazer" jornalístico. Eu próprio nunca me senti estranho, nos territórios mediáticos pluridisciplinares que pratiquei e pratico, por causa da minha formação jurídica. Bons jornalistas de nome feito neste país são oriundos de escolas económicas, ou médicas, ou técnicas. Nada contra isso. O jornalismo faz-se, em Portugal, muito antes de começar a ser ensinado em escolas especializadas.

O que se requer, notoriamente, é um ajustamento competente e severo do húmus cultural e referencial, dos aspirantes a uma matriz comunicacional, às características do próprio território que almejam pisar. $\mathrm{E}$ isso chama-se formação.

Se as escolas de jornalismo tivessem meios e humildade para se ocuparem do fracasso laboral dos seus melhores resultados curriculares, Portugal veria nascer de imediato um grupo de centros técnico-profissionais de Jornalismo, complementares aos actuais programas de ensino académico. Centros onde a ciência académica fosse exigida como ponto irrecusável para uma entrada na aprendizagem prática, mas onde os alunos encontrassem uma visibilidade factual dos ensinamentos adquiridos. E aí sim, ensino e formação poderiam casar-se in situ, organicamente, utilmente.

Até lá seremos todos, agentes ou receptores activos e passivos desta situação, partes de um sofisma velho e dispensável: um ensino incapaz de formar, uma formação incapaz de o ser.

\section{Análise e investigação}

Hália Costa Santos*

Os aspectos que considero centrais na formação de jornalistas são três: conhecimento da realidade em que vivem, desenvolvimento das técnicas específicas da profissão e aperfeiçoamento do domínio da língua portuguesa. Estes três aspectos não devem, na minha opinião, ser apresentados num qualquer tipo de hierarquia, podendo antes ser conjugados e, sempre que possível, interligados.

* Jornalista. Docente na Escola Superior de Tecnologia de Abrantes, Instituto Politécnico de Tomar. 
No conhecimento da realidade em que vivem incluo logo à partida uma referência constante à actualidade, para além de abordagens mais específicas aos mundos da política, da economia, da justiça, da cultura e da sociedade em geral. No desenvolvimento das técnicas específicas da profissão incluo um entendimento claro dos diferentes géneros jornalísticos, assim como a sua aplicação prática. Neste campo é ainda fundamental uma informação completa sobre as normas éticas e deontológicas pelas quais se rege a actividade. Finalmente, o aperfeiçoamento da língua portuguesa como aspecto central fica a dever-se a dois factores: às dificuldades manifestadas pelos jovens que ingressam nos cursos superiores de comunicação social e/ou jornalismo; ao papel de "formadores" da população que irão ter enquanto jornalistas, sendo imperdoável o desconhecimento da língua materna que será, também, a sua principal ferramenta de trabalho.

Embora com alguma dificuldade em considerá-los "secundários", chamaria para um patamar mais abaixo os seguintes aspectos: conhecimento do panorama dos media portugueses e da sua organização interna; consciência clara sobre as características dos diferentes media (jornal/rádio/televisão/agência/on-line); conhecimento das teorias da notícia e da comunicação; domínio das novas tecnologias; debate sobre as questões da actualidade internacional; domínio de línguas estrangeiras (pelo menos mais uma para além da língua portuguesa); desenvolvimento de noções de Direito, Economia, Sociologia e Estatística aplicadas às necessidades do exercício da profissão. Também aqui encontro alguma dificuldade na tentativa de hierarquizar.

Finalmente, considero que existe uma outra componente que não deve ser deixada de lado na formação de nível superior dos jornalistas: análise e investigação. Ao serem estimulados a fazer uma leitura crítica do produto jornalístico, os futuros profissionais estarão em condições de melhor saberem que linhas de orientação deve seguir o jornalismo de qualidade. Para além de se tornarem mais atentos ao que se faz e ao como se faz, este exercício de análise e de investigação pode também abrir-lhes outras perspectivas, nomeadamente a de uma carreira académica.

\section{A formação no equilíbrio}

Helder Bastos*

A formação dos jornalistas deverá basear-se na permanente busca do equilíbrio entre a sólida construção teórica e a indispensável proficiência prática. A excessiva valorização de uma em detrimento da outra tende a gerar distorções, umas vezes no campo académico, outras vezes no terreno das redacções. Ora, em certos casos verifica-se que o ensino superior nesta área não cuida de acautelar devidamente o equilíbrio formacional dos futuros jornalistas, resultando daqui contributos para uma indesejável perpetuação do desnivelamento entre as salas de aula e as redacções.

* Docente do curso de Jornalismo e Ciências da Comunicação da Universidade do Porto; ex-editor da redacção Norte do Diário de Notícias. 
A crescente complexidade do exercício da actividade jornalística - da problemática das questões éticas e deontológicas, passando pelos desafios colocados pelas novas tecnologias, até à reconfiguração do enquadramento económico e financeiro que envolve as empresas jornalísticas - no quadro de uma sociedade que se aprofunda e complexifica nas suas mais diversas áreas de actividade, autoriza escassa margem para a formação superior de base que não seja em ciências da comunicação e jornalismo.

A profissão ganharia em encaminhar-se gradualmente para um modelo comum que garantisse uma formação superior idêntica para os profissionais da classe que, depois de terminado o curso, poderiam optar por uma pós-graduação em determinadas áreas, como economia, saúde, ciência ou outras. O processo inverso afigura-se contraproducente. A heterogeneidade resultante da adopção deste modelo não poucas vezes tem redundado numa porventura exagerada fragmentação, quer de princípios, quer de propósitos. Cada profissional faz uma espécie de interpretação livre do exercício do jornalismo, desconhecendo-se, ou menosprezando-se, em muitos casos, as mais elementares regras da profissão.

O mundo académico deve pois procurar o reforço da base teórica, não só em temáticas abrangentes relacionadas com as mais diversas ciências sociais, mas também - quiçá, sobretudo - nas disciplinas específicas orientadas para enquadramento e problematização: sociologia do jornalismo, teoria da notícia, ética e deontologia, etc. É fundamental o contributo da universidade para que o jornalismo seja cada vez mais pensado e não apenas praticado. Nenhum aluno ou ex-aluno pode chegar a uma redacção sem ter uma ideia que seja sobre o Código Deontológico.

A formação prática dos estudantes de jornalismo não é menos problemática. Embora seja voz corrente dizer-se que jamais o ambiente, as exigências, as contingências e até a cultura das redacções serão passíveis de reprodução em "laboratório" universitário, o que é em boa parte verdade, não devemos resignarmo-nos à inevitabilidade desta distância. Tudo o que não for reproduzível poderá de alguma maneira ser simulável, de forma a que o estudante adquira técnicas, ritmos e noções práticas que o aproximem, tanto quanto possível, do trabalho jornalístico corrente. Nenhum aluno ou ex-aluno de jornalismo pode chegar a uma redacção sem saber como redigir uma simples notícia de quatro parágrafos.

\section{Formação universitária é fundamental}

Ivone Dias Ferreira*

Se o jornalismo e os jornalistas são objecto de discussão é porque se lhes atribui, de uma forma geral e cada vez mais, um grande poder. Acredito que o tenham. Por isso, ser jornalista implica também uma crescente responsabilidade social. Hoje nada escapa ao fenómeno informativo e ao modo como ele é comunicado.

Há apenas algumas décadas escolhiam-se os jornalistas que entravam nos jornais, na rádio ou na televisão apenas porque possuíam "queda" para a escrita, uma boa

* Assessora de Imprensa do Ministro da Educação. 
voz ou um "palminho de cara”. Hoje, uma formação universitária adequada é fundamental. E adequada não quer dizer, obrigatoriamente, uma licenciatura em Comunicação Social.

O maior problema na formação não se prende, na minha opinião, com o curso superior que se obtém numa qualquer universidade. O que é cada vez mais urgente, e não se adquire apenas porque se obtém o "canudo", é a existência de certos valores e qualidades associadas ao perfil dos jornalistas.

Ser jornalista pressupõe um conhecimento profundo do terreno que se pisa, do assunto sobre o qual se escreve. Pressupõe que o profissional tenha uma excelente agenda de contactos, que saiba recolher a informação e fazer as perguntas certas no momento certo. Que seja intuitivo. Que perceba os tons de voz, as formas diferentes de olhar, os sorrisos ou os esgares dos seus entrevistados...

O facto de estar, há mais de dezoito meses, do "outro lado", permite-me hoje analisar como os diferentes media e os diferentes jornalistas tratam a informação que lhes é dada.

E essa diferença de tratamento tem a ver, sobretudo, com a forma como cada um se posiciona. Desde os que dizem que querem ouvir, mas não ouvem, os que tratam tudo pela rama, até aos que de uma forma honesta trabalham a informação, já encontrei um pouco de tudo.

Acreditem que, por muita ternura que tenha pelos recém-saídos das universidades, não posso deixar de dizer que prefiro... os mais velhos. Neles encontro, mais frequentemente, maturidade, ponderação, calma. Capacidade de reflexão antes de se lançar para o computador e escrever a primeira frase, partindo de juízos pré-elaborados ou de opiniões pouco fundamentadas na razão...

E o gosto continuado de aprender e apreender. O sentido de justiça. A capacidade de reconhecer que também pode errar.

Isto não se aprende na universidade. Aprende-se com a vida.

\section{Para lá do aparente}

João Aguiar Campos*

1. É conhecida a cena do guia que, na cabeça do grupo, desce do seu cavalo, observa os rastos e, ajoelhando, cola o ouvido ao chão. Depois, anuncia aproximações ou afastamentos...

Vem-me esta imagem à memória, porque considero o Jornalista este homem capaz de ver e ouvir mais que a realidade aparente; capaz de ir mais longe do que o escrupuloso e factual relato de um acontecimento.

Esta é, no entanto, uma missão que requer preparação consistente - sendo cada vez mais verdadeira a afirmação de Joseph Pullitzer, que surpreendeu boa gente do seu tempo: os jornalistas não nascem; formam-se. 
2. Do contacto laboral com jovens licenciados nos nossos cursos de Comunicação, extraio, entretanto, a necessidade prioritária de uma formação que recuse identificar-se com a mera capacidade técnica.

Mais do que esta - e sem dela prescindir - importam, de facto, os conteúdos que o Curso de Ciências de Comunicação tem de recolher em disciplinas que fazem parte de outros currículos académicos: História do Pensamento Político, Filosofia, Sociologia, etc. Enfim, estudos que estruturem o saber, de modo que a precisão da forma não seja traída pela inconsistência e incapacidade de contextualizar e dar significado.

Uso a metáfora de empreiteiro: garantida a segurança, cuidaremos, com meticuloso cuidado, dos acabamentos... No caso que agora nos ocupa: dos estilos e géneros; de tudo aquilo que diz respeito aos dispositivos que a técnica vai colocando ao serviço das mensagens e dos mensageiros.

3. Uma outra componente que gostaria de ver solidamente incorporada no currículo do futuro jornalista é a profunda reflexão sobre a dimensão ética da profissão.

Penso que muito do Jornalismo que hoje se faz chama a atenção para este facto: não basta que se conheçam e respeitem minimamente as leis que regulam o seu exercício. Importa, pois, ir mais longe e considerar que a responsabilidade pessoal não se esgota na responsabilidade civil.

A este propósito, cito - e suponho que com suficiente fidelidade - a afirmação de um especialista em Ética da Comunicação: o profissional não informa bem apenas porque cumpre um conjunto de deveres, mas porque procura fazer o bem com a sua profissão!...

\section{0 papel das humanidades}

Joaquim Vieira*

O problema do currículo dos cursos de ciências da comunicação em Portugal - os únicos que fornecem licenciaturas em jornalismo - é que são elaborados por académicos que raramente possuem experiência da profissão. Os cursos de arquitectura são dirigidos por arquitectos, os de engenharia por engenheiros, os de medicina por médicos, mas nada disso se passa com os cursos de jornalismo. Com estágio ou sem ele, os diplomados não saem das escolas preparados para exercer a carreira, e é na prática, quando já estão a trabalhar, que aprendem como se faz jornalismo, herdando o saber mas também os vícios que os colegas mais antigos (mas nem por isso mais conhecedores, pois muitos deles também passaram pelos mesmos equívocos) lhes vão transmitindo. Todos os defeitos daí resultantes podem ser detectados numa análise minimamente crítica ao estado actual do jornalismo português.

Tendo também ministrado aulas num curso de ciências da comunicação, posso declarar, com conhecimento de causa, que a primeira carência nas escolas consiste nas

* Presidente do Observatório da Imprensa. 
diversas disciplinas de humanidades que fornecem a um jornalista a base mental capaz de fazer dele um bom profissional.

Em primeiro lugar, o domínio da língua, o mais essencial instrumento de trabalho. Os futuros profissionais devem aprender o Português (porque, nessa matéria, vêm escandalosamente impreparados do secundário) e a literatura em língua portuguesa, mas também adquirir conhecimentos de literatura estrangeira. Não é só o domínio das formas de expressão que assim se aprende, é também o contacto com as ideias e o drama da existência humana - de que o estudante virá a ser o futuro cronista.

Deve depois conhecer a História, toda ela, portuguesa e mundial, mas com especial incidência nos últimos dois séculos e meio, em que se formaram as tendências do pensamento contemporâneo, e na história das ideias (no contexto da evolução da filosofia e das ciências, e com destaque para as ideias políticas). Só este conhecimento permite compreender (ou pelo menos contextualizar) os fenómenos que o candidato a jornalista se encarregará mais tarde de registar e comunicar ao seu público.

A seguir, duas disciplinas obrigatórias para uma melhor compreensão da sociedade contemporânea: o Direito e a Economia. Sem elas, o jornalista ficará apenas pela superfície de muitos acontecimentos determinantes. Existem nos currículos de muitos cursos de comunicação, mas será que são ministradas com verdadeira preocupação de ensinar?

É também fundamental a prática fluente do Inglês, língua franca no sector mediático - e em todos os outros.

Falta ainda o aprofundamento da Técnica Jornalística, que, já existindo, é abordada de forma muito ligeira, sem reflexão e a necessária avaliação no domínio da sua prática.

Por último, a Ética, que dá ao jornalista a consciência da sua responsabilidade social e o obriga a acatar os elevados padrões que isso implica.

Para um bom curso de jornalismo, eu trocava o excesso de exegese semiótica e de teorias comunicacionais por tudo isto. Mas a mim parece-me que esses cursos se destinam a formar académicos, não jornalistas. Se assim for, então está tudo bem.

\section{Sete núcleos fundamentais}

Jorge Wemans*

Apesar de leccionar num curso de Comunicação Social, sou dos que preferia perspectivar a formação de jornalistas a partir de licenciados em outras áreas. Em qualquer caso, pelo que percebo dos condicionalismos que hoje formatam a actividade jornalística, tal formação deveria passar sempre pelos seguintes núcleos fundamentais (cuja designação procuro apresentar, quando possível, do modo a que não se confunda com as existentes). Dos sete núcleos, três dizem directamente respeito às ferramentas próprias do exercício da profissão, os outros quatro organizam áreas de conhecimento que julgo indispensáveis: 
1. Técnicas de redacção e linguagens jornalísticas

As ferramentas fundamentais da comunicação jornalística, adaptadas aos diferentes meios e estilos. A linguagem própria de jornais, rádios, televisões e da web.

\section{Leitura e análise dos media}

Aos futuros jornalistas não se pode apenas exigir que conheçam as técnicas próprias do seu ofício. É necessário que saibam "ler" de forma adequada, com base em instrumentos de análise rigorosos, os próprios media. De certa forma, o que pretendo assinalar é a necessária educação (avançada) para os media.

\section{Deontologia jornalística}

Perante a crise do estatuto profissional do jornalista, a Deontologia ganha nova actualidade como compromisso pessoal e colectivo com práticas que respeitam o público, as fontes e os nomeados.

\section{A democracia e os sistemas políticos e eleitorais}

A Democracia não se esgota nos diferentes sistemas de governação dos Estados Democráticos, mas é preciso conhecer os fundamentos daquela e o estudo comparado destes (para que se perceba a diferença entre o lugar e funções da Rainha de Inglaterra e do Presidente dos EUA). A organização democrática dos Estados é também diferente: Repúblicas, Monarquias, Estados Federais: atribuições e funções administrativas das diversas instâncias; a organização do processo legislativo e do processo eleitoral.

\section{Economia portuguesa no contexto da UE}

Não se trata de Introdução à Economia, mas sim de situar a Economia Portuguesa no contexto da UE. Questões demográficas nacionais; principais centros de decisão; principais indicadores; contas públicas - como ler um Orçamento do Estado - principais dilemas; políticas fiscais; contributos sectoriais para o PIB; assimetrias regionais; pobreza e desemprego; vantagens comparativas; estrangulamentos crónicos.

\section{Introdução ao Direito e ao Processo Penal}

Não se trata de Introdução ao Direito, mas sim de situar a importância relativa da legislação, desde a Constituição até ao despacho municipal. Organização da Justiça: magistraturas, tribunais; ministério público; polícias e forças de segurança; advocacia; etc... Favorecer a compreensão de como funciona a Justiça, desde a investigação policial até à aplicação de penas.

\section{A União Europeia}

História e momentos-chave. O processo de decisão na UE. Principais políticas comuns. Estruturas e organização da União. O futuro da UE. Federalismo e antifederalismo. Lugar de Portugal no contexto das relações internacionais e dos tratados de Defesa do país e da União. 


\section{0 papel da teoria}

Lopes de Araújo*

Comecei a minha carreira profissional numa altura em que eram praticamente inexistentes os cursos superiores de comunicação social. Por isso fiz a minha formação académica na área do Direito, onde acabei por me licenciar. Em 1976, acabado de entrar na RTP, participei como formando no primeiro Curso de formação de jornalistas feito na empresa, em conjunto com outros colegas de então como o Fernando Balsinha, recentemente desaparecido, o Pedro Luís de Castro, a Manuela de Melo e a Fátima Torres, do Centro do Porto, entre outros. A RTP criou naquela altura um Centro de Formação que veio muito justamente a ser considerado, no final dos anos setenta, a par com o da NOB-Holandesa, um dos mais completos e eficazes da Europa. Algum tempo mais tarde fui monitor nesse Centro de Formação, numa época em que Portugal recebeu uma marcante ajuda na formação audiovisual com a participação de Edouard Guibert à frente de uma equipa de formadores do INA (Institut National de l' Audiovisuel) de Paris. Quase vinte anos mais tarde, Edouard Guibert voltaria a Portugal para formar a equipa de jornalistas que iria arrancar com a primeira estação privada de televisão - a SIC. Infelizmente Edouard Guibert, que foi Director de Informação da FR3, faleceu há cerca de um ano depois de ter marcado gerações de jornalistas em França e em Portugal.

Aquilo a que então se procurava responder era ao vazio na formação dos novos jornalistas que entravam na profissão no conturbado período que se viveu a seguir à revolução de Abril. Na televisão, a formação visava em primeiro lugar a reflexão sobre aspectos sociais do fenómeno televisivo e em particular os resultantes da informação televisiva; depois, o domínio do dispositivo técnico, quebrando um fosso de muitos anos entre jornalista e equipamentos, estes um segredo bem guardado e herdado da chamada era dos Engenheiros. Finalmente o controlo da reportagem, da entrevista, da apresentação e das técnicas de escrita para televisão. No seu conjunto a formação era feita por módulos teóricos e práticos levando à produção de trabalhos que acabavam por fazer parte de um Telejornal completo gravado em estúdio, produzido e realizado pela equipa de formandos.

Perdoem-me a evocação pessoal, mas foi apenas para dizer que, no que respeita ao jornalismo televisivo, quase trinta anos depois, essa orientação continua a fazer parte de muitos dos programas de cadeiras de televisão em licenciaturas de jornalismo ou de Comunicação Social. Usei-a em Coimbra e ainda a uso na Universidade Católica.

Parece-me que no contexto em que hoje se exerce a profissão e para além das cadeiras específicas dos vários ramos do jornalismo, são particularmente importantes as cadeiras de ética e deontologia profissionais que merecem ser dadas com grande rigor e exigência. Do mesmo modo, afigura-se-nos do maior interesse que as cadeiras de for- 
mação jurídica, económica e de ciência política ocupem parte substancial na composição curricular dos referidos cursos, já que constituem um lastro da maior importância na formação do futuro jornalista.

Sou dos que acreditam que na Universidade não se fabricam jornalistas, mas ajuda-se a despertar a vocação e dá-se a formação essencial ao desempenho futuro da profissão. Nesse sentido, creio que a existência de uma componente prática, composta de trabalhos nos laboratórios de rádio, televisão e imprensa, completados, depois, pelo estágio, são igualmente um elemento importante da formação do jovem estudante de Jornalismo. Porém, a prática vem depois no dia-a-dia de uma redaç̧ão. E a teoria, esta é que já não se aprende senão na Universidade...

\section{Do fim para o princípio}

Luísa Bessa*

Lembro-me, como se fosse hoje, do meu primeiro dia na redacção do Jornal de Notícias. Um pormenor marcou-me particularmente: o frasco de tinta cheio de goma arábica, o pincel e a grande tesoura que me passaram para as mãos, e a explicação de que seriam esses os principais instrumentos da minha prática jornalística.

Passou-se isto há pouco mais de 20 anos, ainda as universidades portuguesas não ofereciam cursos de comunicação e toda a formação era feita, como se dizia, na tarimba. A fazer, a ver fazer os outros, a receber as críticas do chefe, que virava a prosa de pernas para o ar.

A formação que me coube, ainda antes disso, foi a leitura do manual do Cardet, onde aprendi a técnica da pirâmide invertida e algumas coisas mais, e uma boa dose de interesse pela actualidade, que solidificou aquilo que podia considerar-se uma boa cultura geral. E assim consegui passar pelo buraco da agulha e começar o meu percurso de estagiária. Claro que saber escrever - pontos finais e vírgulas no sítio certo, ortografia correcta, texto compreensível, que o brilhantismo ainda não é para aqui chamado também ajudou.

Pedem-me uma reflexão sobre os aspectos centrais para a formação do jornalista. As recordações dos tempos idos dão algumas pistas sobre o que penso sobre isso. Porque, apesar de a cola e a tesoura terem desaparecido das secretárias, ainda sobrevive muito jornalismo de corta e cola, além de coisas piores.

O primeiro requisito é, então, uma sólida formação na língua portuguesa. Escrever correctamente é fundamental, entendido como a capacidade de organizar um texto, exprimir as ideias com clareza. O conhecimento das técnicas jornalísticas é o segundo. É verdade que a escrita jornalística pode tornar-se monótona e pouco criativa, mas para inovar há que ter as bases a partir das quais é possível fazê-lo. A experiência que

* Jornalista, subdirectora do Jornal de Negócios. 
vou tendo com jovens licenciados em comunicação ou em fase de estágio curricular é muito irregular. O conceito de notícia e as suas consequências na elaboração dos textos não estão, em muitos casos, bem apreendidos.

Como há 20 anos, é também necessária uma boa cultura geral. Entendamo-nos: não falo de conhecimento livresco para ter sucesso em concursos do tipo "O elo mais fraco" ou quejandos (embora saber nomes e datas não faça mal a ninguém e a capacidade de memória para factos e personagens seja importante para um jornalista). Falo de conhecimento da História de Portugal e da evolução do Mundo nas últimas décadas, falo de noções de geografia, falo do domínio do inglês e/ou de outras línguas, falo da capacidade de lidar com números. Temos que acabar com a incompatibilidade entre as formações em ciências humanas e a matemática. Porque o desprezo pelos números conduz a uma gritante falta de preocupação com o rigor e a exactidão que são, em meu entender, pecados graves do jornalismo nacional.

O conhecimento das leis da comunicação, a capacidade relacional e a curiosidade são também aspectos importantes. Como o é o domínio das tecnologias.

Deixo para o fim o ponto crítico: a ética e a deontologia. Sem dominar tudo o resto de que antes falei não se consegue ser um bom jornalista. Mas dominando esses aspectos e faltando uma forte referência ética sobre os limites inultrapassáveis não há bom jornalismo que resista, como tem sido facilmente verificável em exemplos recentes (falemos apenas do New York Times e do caso Kelly/BBC, para não melindrar os pares).

Dir-me-ão que os jovens jornalistas chegam às redacções e têm que dançar ao som da música. O mercado é limitado e grande a concorrência por um posto de trabalho. Também sei que para vingar em determinados meios não são as regras éticas que mais contam. Bem pelo contrário, até podem ser um empecilho. Mas estamos a falar de jornalismo, certo?

\title{
A paixão da rádio
}

\author{
Manuel Vilas-Boas*
}

Tendo em conta a experiência tomada da coordenação de estágios na TSF, há mais de uma década, por onde passam, entre os melhores, os provenientes desta Universidade [do Minho], quero sublinhar como imprescindível, para o exercício da nobre missão de comunicar e informar, a imersão num vasto lago de humildade. Cada vez mais é visível a "luta de classes" no interior das redacções, sobretudo naquelas em que o património da memória, assumido por veteranos da profissão, é delapidado com a exclusão. Trocado, em alguns casos, por rostos de vedetismo fresco ou vozes mais sedutoras, é, em nome de fins inconfessados, incendiado pelo neoliberalismo económico, selvaticamente campeante, que as administrações dos Meios de Comunicação Social traçam, sem qualquer pudor, os desígnios das direcções editoriais. É neste contexto 
que se vive em muitos meios da comunicação social. E porque os tempos são apocalípticos é preciso injectar nos futuros profissionais abundantes doses de ética, para que os jornalistas não se vendam ao marketing de qualquer totoloto.

Cada vez mais é difícil o exercício com dignidade da profissão mais perigosa e mais contestada do mundo. Não servem cursos, barrilados em carteiras tradicionais, onde o saber livresco é exposto por professores presos a metodologias clássicas, vendedores de tédio. Já alguém do Ministério do Ensino Superior reparou que existem em Portugal trinta e três cursos de Comunicação Social, de onde saem, em média, anualmente mais de mil e quinhentos licenciados para três lugares e meio disponíveis no mercado?...

Por outro lado, alunos de comunicação social, que não sabem ler jornais, ouvir rádio, ver televisão, tocar a Internet, dominar a edição de livros e filmes, não podem aspirar a serem mediadores do que acontece no interior das sociedades "do princípio da rua ao fim do mundo". Ninguém, sem paixão, vai ser capaz de vencer a inércia do quotidiano cinzento. Ninguém, sem vocação, vai tolerar o desgaste, mesmo físico, da tensão e do stress, da "última hora", que leva ao cemitério os profissionais, em médias etárias que não ultrapassam as seis décadas. Que notícia, que golpe de Estado, que situação de emergência pode conduzir a tão irracional martírio?

Se a síntese pode estar à vista, tudo o que possa conduzir à máxima maturidade intelectual e cultural do formando, pela vivacidade com que prova consumir a realidade, tudo o que o faz próximo da cidadania e da história, tudo o que o eleva ao respeito pela verdade, vai torná-lo capaz de transmitir mensagens credíveis. Não é jornalista quem quer, é jornalista quem ama os espectadores, os ouvintes, os leitores como a si próprio.

\section{Tocar a realidade}

Sara Oliveira*

Quando chegamos à universidade queremos ser tudo, entramos em tudo, lutamos por tudo. Mais que isso, acreditamos em tudo, principalmente na ideia de que cinco anos depois seremos jornalistas. Depois ouvimos os primeiros acordes do curso, seguidos de estrofes inteiras, que é como quem diz, as cadeiras, as matérias, as primeiras discordâncias, os primeiros medos. Queremos, ainda assim, ser jornalistas. Mas começamos a não saber se o vamos ser mesmo.

Nos dias que hoje correm não é raro ouvirmos falar mal dos jornalistas - porque mentem, porque exageram, porque prejudicam caras conhecidas, porque estão sempre onde não devem estar. Lá fora, longe dos muros do reduto dos profissionais e dos sonhadores é assim, mas cá dentro as diferenças não são muitas. É frequente falar-se mal do jornalismo que se faz e cada vez são mais abundantes as críticas ao ensino, à fraca formação dos jovens jornalistas, à incapacidade das universidades.

* Presidente do GACSUM (Grupo de Alunos de Comunicação Social da Universidade do Minho). 
Assim que espetamos mais fundo as estacas da nossa tenda no curso que frequentamos, começamos também a pensar sobre tudo isto. Ouvimos conversas no corredor, no convívio com outros colegas e reconhecemos facilmente as falhas no sistema. Muitos dos estudantes de Comunicação Social que pensam um dia vir a ser jornalistas não acreditam que aquilo que aprendem todos os dias, em aulas "chatas", com matérias "inúteis”, os leve ao sucesso no final da linha. A formação superior em jornalismo tem destas coisas - aprendemos muito mais do que apenas a escrever textos jornalisticamente correctos (se é que isso existe), estudamos muito mais do que as regras, os leads, as técnicas, os segredos da profissão. Frequentar uma licenciatura em Comunicação Social, e especificamente a da Universidade do Minho, significa igualmente falarmos de Ciências Sociais, de Filosofia, de Economia, de Estatística. "Uma seca!", ouço tantas vezes. E na verdade, muitas vezes, é mais fácil pensar assim. Porque não gostamos do professor, porque reprovámos na primeira frequência, porque a matéria não nos interessa. No futuro, o que nos custará mais ainda do que custou assistir a essas aulas será admitir que tiveram alguma utilidade, que nos ajudaram a estar no lugar em que estivermos.

Não acredito na ideia de que temos a formação perfeita - faltam-nos mais horas a escrevinhar sem parar, cadeiras mais próximas dos novos meios, mais oportunidades para experimentar em infra-estruturas mais disponíveis. Mas acredito que na formação de um bom jornalista toda a teoria de que não gostamos, que nos desespera em épocas de exame e toda a bagagem académica e cultural com que saímos de um curso superior são essenciais. Não nos faz escrever melhor, não dá um toque de génio a um 'directo', nem torna mais fácil dizer aquela palavra complicada aos microfones de nenhuma rádio. Mas torna-nos cidadãos e jornalistas mais conscientes, capazes de reflectir sobre o mundo em que trabalhamos, um mundo em mudança cada vez mais acelerada, no qual facilmente nos podemos perder. A isto é essencial que se junte o trabalho pessoal do aluno, que deve explorar todas as potencialidades do curso. Se a prática não está lá desde o primeiro ano, então há que procurar saídas, experiências, colaborações, como nos jornais académicos. Jornalismo não se aprende só dentro das salas de aula é preciso sair, tocar a realidade, aprender com ela, reflectir. E essa reflexão não se consegue com meras aulas de gramática. Um bom jornalista não se consegue com aulas de gramática. 